\title{
CORRIGENDUM
}

\section{Postpartum traditions and nutrition practices among urban Lao women and their infants in Vientiane, Lao PDR}

\author{
H Barennes $^{1}$, C Simmala ${ }^{1}$, P Odermatt ${ }^{2}$, T Thaybouavone ${ }^{1}$, J Vallee $^{3,4}$, B Martinez-Aussel ${ }^{1}$, \\ PN Newton ${ }^{5,6}$ and M Strobel ${ }^{1}$

\begin{abstract}
${ }^{1}$ Department of Epidemiology, Institut Francophone pour la Médecine Tropicale, Vientiane, Lao PDR; ${ }^{2}$ Department of Public Health and Epidemiology, Swiss Tropical Institute, Basel, Switzerland; ${ }^{3}$ Institut de Recherche pour le Développement UR 178, Vientiane, Lao PDR; ${ }^{4}$ Laboratoire Espace, Santé et Territoire, Université Paris X-Nanterre, Nanterre, France; ${ }^{5}$ Wellcome Trust-Mahosot Hospital-Oxford University Tropical Medicine Research Collaboration, Mahosot Hospital, Vientiane, Lao PDR and ${ }^{6}$ Centre for Tropical Medicine, Churchill Hospital, University of Oxford, Oxford, UK
\end{abstract}

European Journal of Clinical Nutrition (2009) 63, 450; doi:10.1038/sj.ejcn.1602975

Correction to: European Journal of Clinical Nutrition (2009), 63, 323-331; doi:10.1038/sj.ejcn.1602928.

Since the online publication of this article on 14 November 2007, the authors have identified that not all of the affiliations were included for various authors. The name of the author B Martinez-Aussel was also spelt incorrectly. The correct affiliations and authors' name are shown above. 